\title{
Exercise as an addictive behavior: Implications for building awareness in the community
}

\author{
Manoj Kumar Sharma ${ }^{1 *}$, Girish N Rao ${ }^{2}$, Vivek Benegal ${ }^{3}$, Thennarasu K ${ }^{4}$, Hamza $A^{5}$ and Divya Thomas ${ }^{6}$ \\ ${ }^{1}$ SHUT clinic (Service for Healthy use of Technology), National Institute of Mental health \& Neurosciences, Bengaluru, Karnataka, India \\ ${ }^{2}$ Department of Epidemiology, Centre for Public Health, National Institute of Mental health \& Neurosciences, Bengaluru, Karnataka, India \\ ${ }^{3}$ Department of Psychiatry, Centre for Addiction Medicine, National Institute of Mental health \& Neurosciences, Bengaluru, Karnataka, India \\ ${ }^{4}$ Department of Biostatistics, National Institute of Mental health \& Neurosciences, Bengaluru, Karnataka, India \\ ${ }^{5}$ Psychiatry Social work National Institute of Mental health \& Neurosciences, Bengaluru, Karnataka, India \\ ${ }^{6}$ Department of clinical Psychology, NIMHANS, Bengaluru, India
}

\begin{abstract}
Exercise is being associated with feeling of wellbeing. But it also leads to manifestation of withdrawals on discontinuation. The present study is going to explore the pattern of exercise behavior in Indian context. 2755 (1392 males and 1363 females) subjects in the age group of 18-50 years were approached for administration of sociodemographic data sheet, General Health questionnaire, Exercise addiction inventory 5.8\% were at risk category of exercise addiction and gender difference was present same. Psychiatric distress had negative correlation with exercise addiction. $01 \%$ show the need for change in the exercise pattern. It has implication for enhancing the mental health professional understanding of exercise addiction.
\end{abstract}

\section{Introduction}

Exercise, which is one of the healthy behaviors, can become an obsessions for exercisers. Indian youth and older group indulge themselves in one or other form of exercise i.e. gym, running, walking, yoga and meditation. It can take the form of addiction. i.e. experiencing craving for exercise, loss of control, compulsion to indulge in exercise, reduction in other activities and consequences in relation to exercise. The effect of exercise deprivation on sleep pattern was seen among subjects reported problems in managing day without exercise for two consecutive days [1]. Later, it got popularized as positive addiction [2]. The exercisers reported the presence of withdrawals i.e. irritability negative mood states whenever denied the opportunity to engage in exercise. $8 \%$ of gym users had exercise addiction [3]. Three percent of exerciser's reported that they could not stop exercising [4].

From psychophysiogically perspective endorphin hypothesis is the commonly used explanation for understanding exercise addiction, as per the hypothesis, exercise produce endogenous morphine which leads to positive mood states [5]. There is a need to differentiate it from recreational use of exercise. It can be assessed from user motivation(it is a control but pleasurable \& rewarding activity);consequences( absence of consequences to user start organizing his/her day around exercise; started using exercise as a method of coping and other psychosocial consequences) and frequency \& control( control activity without any consequences to users started engaging in it though it is not required off; loss of control in relation to exercise; no longer a rewarding activity ;activity used to avoid withdrawals) [6].

It is emerging area of research for mental health professional to understand the continuum of positive addiction to exercise addiction. There are few empirical studies from Indian context. It is one of its kind first documentation of addictive potential of exercise.

\section{Materials and methods}

The study explored the pattern of exercise behavior in the community.

\section{Tools}

Socio-demographic profile data sheet: It was prepared by the researcher for collecting socio-demographic information on psychosocial variables related exercise.

Exercise addiction Inventory (EAI): It's a six-item scale. It identifies the people at risk for developing exercise addiction. It got good internal reliability \& validity. The EAI has good internal reliability (Cronbach a $=.84)$. Its concurrent validity with the Obligatory Exercise Inventory5 was $r=0.80$, and with the Exercise Dependence Scale6 was $r=0.81$. Its test-retest reliability was $r=0.85$. Individuals scoring above 24 on the EAI may be classified as "at risk" of exercise addiction. the other group are symptomatic group (13-23) and normal (less than 13) [7].

General health Questionnaire - 5. It is stage screening tool with validity of sensitivity of $86 \%$, specificity of $89 \%$. It has a cutoff point of $3 \&$ above for indicating presence of psychiatric distress [8].

${ }^{\star}$ Correspondence to: Manoj Kumar Sharma, Professor, Dept of Clinical Psychology, SHUT clinic (Service for Healthy Use of Technology), NIMHANS, Bengaluru, India, Tel: +919341664401; E-mail: shutclinic@gmail.com

Key words: exercise, addiction, psychosocial variables

Received: February 08, 2019; Accepted: February 21, 2019; Published: February 25,2019 


\section{Procedure}

2755 (1392 males and 1363 females) subjects in the age group of 18-65 years, were approached from Urban localities of East Bangalore, Karnataka, India for individual administration of schedule (sociodemographic data sheet, General Health questionnaire, Exercise addiction inventory) using house to house survey. Subjects with inability to read \& write English were excluded from the study. The profile of residents in these areas included wider representation of all economic classes. The attempt was made to include equal number of subject in each group $(18-20 ; 21-25 ; 26-30 ; 31-35 ; 36-40 ; 41-45 ; 46-50 ; 51$ $55 ; 56-60 ; 61-65$. The minimum number of individuals in each age group were 60 .At least 3 attempts were made to develop contact with the residents before they were considered as dropout. The surveyors were holder of post graduate degree in social science and were trained in administration of tools as well as to carry out survey.

\section{Results}

36.48 years was the mean age of the sample. $50.5 \%$ of the participants were males, $49.5 \%$ of them were females. $27.1 \%$ were graduates, $10.7 \%$ were postgraduates, $24.1 \%$ were secondary education, $21.1 \%$ were having higher secondary/PU education and $9.9 \%$ were primary educational background. $5.8 \%$ of the sample were having technical/ITI education, where as $1.2 \%$ were illiterate. $7.5 \%$ of the sample was single; $66.7 \%$ were married, $5.1 \%$ were widowed \& divorced or separated category constitutes $0.6 \%$. 9\% of unmarried people had exercise addiction, 3.9\% of married people reported to have exercise addiction and $9.8 \%$ and $2.2 \%$ of widowers \& divorcees were also reported exercise addiction. Psychiatric distress was present among 7.4\%(N=20) subjects at risk for addiction;57.6\%(N=156) for symptomatic group and $35.1(\mathrm{~N}=95)$ in the normal group. $01 \%$ show the need for change in the exercise pattern. The subjects did not report history of substance use or met the current or life criteria for dependence

Table 1 indicates 1743 participants reported to be doing exercise regularly. 102 participants come under at risk for exercise addiction (5.8\%) (7.5\% males \& 3.8 females), 1094 individuals belong to symptomatic group (63\%) and 647(37\%) were in normal exercise group.

Table 2 indicate the significant gender difference in relation to exercise addiction.
Table 3 showed the negative correlation of age, members at home, years of marriage and psychiatric distress with exercise addiction.

\section{Discussion}

The present study document the presence of $5.8 \%$ having exercise addiction among among1743 subjects in the age range from 18-50 years (Table 1). The presence of exercise addiction varied in relation to gender. It was more among males (Table 2). It was more among unmarried subjects. All the three group of exercise addiction inventory showed the presence of psychiatric distress. It was $5.8 \%$ in the at risk for addiction group. Age, number of members in the family, years of marriage and psychiatric distress had negative correlation with exercise addiction (Table 3). These findings is one of its kind in relation to exercise addiction in Indian context.01\% expressed the need to change their exercising behaviors. The obtained percentage of at risk for exercise addiction was comparable to international studies in this area. It was estimated from $3 \%$ to $5 \%$ of the U.S. college youth population [9]. The prevalence in the general population was close to $3 \%$ [10]. It was found to be higher among certain groups such as runners [11]. Whereas other studies among college youth report prevalence as high as $21.8-25.6 \%[12,13] .42 \%$ of the members at a Parisian fitness club met criteria for exercise addiction [14]. The varying percentage could be due to variation in sampling frame used for the respective study. The exercise was reported to be inversely related to anxiety and depression $[15,16]$.

Limitation and Strength: The present study has limitations in form of not having qualitative data to understand the process of addictive use of exercise as well as user knowledge about the addictive potential of exercise. The present study did not have information about the time spent on exercise as well as type of exercise (with supervision and without supervision) they used.

\section{Future studies}

The present study has implications for enhancing the mental health professional understanding of exercise addiction and its association with psychosocial variables. It also implies the enhancing community awareness for addictive potential of exercise. There is a need to build up empirical literature in this area to understand the etiology/ conceptualization of exercise addiction

Table 1. Showing frequency of exercise addiction

\begin{tabular}{|c|c|c|c|}
\hline Exercise addiction Score range & Participants doing exercise regularly & Frequency \\
\hline $0-12$ (normal) & & 647 & 37.119 \\
\hline $13-23$ (symptomatic) & 1743 & 1094 & 62.765 \\
\hline $24-30$ (at risk for addiction) & & 102 \\
\hline
\end{tabular}

Table 2. Relationship of exercise addiction with gender

\begin{tabular}{|c|c|c|c|c|c|c|c|c|}
\hline \multirow{2}{*}{ Variables } & \multicolumn{3}{|c|}{ Female } & \multicolumn{3}{|c|}{ Male } & \multirow[b]{2}{*}{$\mathrm{F}$} & \multirow[b]{2}{*}{ Sig. } \\
\hline & Std. Deviation & Mean & $\mathrm{N}$ & Std. Deviation & Mean & $\mathrm{N}$ & & \\
\hline Exercise addiction & 8.714 & 8.49 & 1,351 & 8.262 & 9.77 & 1392 & 61.37 & 0.00 \\
\hline
\end{tabular}

Table 3. Correlation of exercise addiction with demographic and psychological distress

\begin{tabular}{|c|c|c|}
\hline S. No & Variable \& exercise addiction & $\mathbf{X}^{2}(\mathbf{c h i}$ square) \\
\hline 1. & Age & $-0.079^{* *}$ \\
\hline 2. & Members at home & $-0.059^{* *}$ \\
\hline 3. & Years of marriage & $-0.095^{* *}$ \\
\hline 4. & Psychiatric distress & $-0.077^{* *}$ \\
\hline
\end{tabular}

** 0.001 level 


\section{Funding}

Funding was provided by Indian Council of Medical Research, New Delhi, India.

\section{Disclosure statement}

None.

\section{Ethical approval}

It was approved by Institute Ethic Committee. All procedures performed in studies involving human participants were in accordance with the ethical standards of the institutional and/or national research committee and with the 1964 Helsinki declaration and its later amendments or comparable ethical standards.

\section{Acknowledgement}

The Indian council of Medical Research, Delhi, India awarded the grant to Dr Manoj Kumar Sharma.

\section{Compliance with ethical standard}

There was no conflict of interest in relation to present work as well as informed consent of the human subjects had been taken prior to inclusion in the study.

\section{Disclosure of potential conflict of interest}

Not applicable.

\section{Conflict of interest}

Authors of the paper did not have any conflict of interest.

\section{Statement of human right}

The studies have been approved by the Institutional and/or national research ethics committee.

\section{Research involving human participants and/or animals}

All procedures performed in studies involving human participants were in accordance with the ethical standards of the institutional and/ or national research committee and with the 1964 Helsinki declaration and its later amendments or comparable ethical standards.

\section{Statement on the welfare of animals}

This article does not contain any studies with animals performed by any of the authors.

\section{References}

1. Baekeland F (1970) Exercise deprivation. Sleep and psychological reactions. Arch Gen Psychiatry 22: 365-369. [Crossref]

2. Glasser W (19767) Positive Addiction, Harper \& Row Publisher 159.

3. Morris M, Steinberg H, Sykes EA, Salmon P (1990) Effects of temporary withdrawal from regular running. J Psychosom Res 34: 493-500. [Crossref]

4. Hartney E (2011) What is Exercise Addiction? When working out becomes an addiction.

5. Griffiths MD, Duff J (1992) Etologies of addictive behavior:a survey of nonprofessionals people's belief. Addiction Res Theor 1: 199-206.

6. Freimuth M (2000) Addicted? Recognizing Destructive Behavior before It's too Late; Rowman \& Littlefield Publishers, Inc: Lanham, MD, USA.

7. Terry A, Szabo A, Griffiths MD (2004) The exercise addiction inventory:a new brief screening tool. Addiction Res Theor 12: 489-499.

8. Shamasunder C, Sriram TG, Murali Raj SG, Shanmugham V (1986) Validity of a short 5-item version of the general health questionnaire (g.h.q). Indian J Psychiatry 28: 217 219. [Crossref]

9. Allegre B, Souville M, Therme P, Griffiths M (2006) Definitions and measures of exercise dependence. Addiction Res Theor 14: 631-646.

10. Sussman S, Lisha N, Griffiths M (2011) Prevalence of the addictions: a problem of the majority or the minority? Eval Health Prof 34: 3-56. [Crossref]

11. Allegre B, Therme P, Griffiths M (2007) Individual factors and the context of physical activity in exercise dependence: A prospective study of "ultra-marathoners". Int J Ment Health Addict 5: 233-243.

12. Garman JF, Hayduk DM, Crider DA, Hodel MM (2004) Occurrence of exercise dependence in a college-aged population. $J$ Am Coll Health 52: 221-228. [Crossref]

13. MacLaren VV, Best LA (2010) Multiple addictive behaviors in young adults: Student norms for the Shorter PROMIS Questionnaire. Addictive Behaviors 35: 252-255.

14. Lejoyeux M, Avril M, Richoux C, Embouazza H, Nivoli (2008) Prevalence of exercise addiction and other behavioral addictions among clients of a Parisian fitness room. Compr Psychiatr 49: 353-358. [Crossref]

15. Biddle S, Mutri N (1991) Psychology of physical activity and exercise, London, Springer, Verlag.

16. LaFontaine TP, DiLorenzo TM, Frensch PA, Stucky-Ropp RC, Bargman EP, et al (1992) Aerobic exercise and mood. A brief review, 1985-1990. Sports Med 13: 160170. [Crossref]

Copyright: (C2019 Sharma MK. This is an open-access article distributed under the terms of the Creative Commons Attribution License, which permits unrestricted use, distribution, and reproduction in any medium, provided the original author and source are credited. 